\section{CHEST EXAMINATION}

By Wing-Commander R. R. TRAIL. J. \& A. Churchill, Ltd., London, $1943 . \quad$ Price 10s. 6d.

Recent strides in radiography of the chest have created the need for a general overhaul of the whole question of physical signs of chest disease. Much simplification should be possible, as many of the time-honoured signs have been proved unreliable.

Trail sets out to correlate the underlying lung pathology with the clinical signs and X-ray appearances. He discusses the applied anatomy of the lungs and bronchi, and deals at some length with pathology as it occurs in the various morbid states. He sums up the clinical findings and the conclusions to be drawn in a section on physical signs, the final section being devoted to the appearance and technique in interpretation of the abnormal X-ray film.

Great emphasis is laid on a division of the inspiratory phase of the breath-sound into three parts. On auscultation an idea of the underlying pathology can be obtained from the intensity of the various adventitious sounds, and more especially the particular part of inspiration in which they occur. Thus there is said to be a stethoscopic difference between pneumonia and bronchopneumonia; between lung abscess and bronchiectasis with lung abscess; between generalised fibrosis and marked peribronchial fibrosis. In the very short section on physical examination much stress is placed on the importance of the sterno-mastoid sign. This is said to be the most constant sign of collapse in all its forms, and more reliable even than screening. Displacement of the apex-beat is mentioned only to be dismissed as "inconstant" or "even misleading."

Quite apart from the above there are many departures from the orthodox. For instance, it is stated that collapse of the right middle lobe produces displacement of the heart. Many will not agree with the assertion that the branching of the bronchial tree is dichotomous. Nor will it be generally accepted that fibrosis produces, widespread rales throughout inspiration remaining after cough. No references are given, even for such a statement as, in speaking of chronic bronchitis, "the vessels in the connective tissue, branches of the bronchial artery, suffer contraction up to endarteritis; this, together with increased resistance to the maintenance of oxygenation tends to produce hypertension."

The diagrams are clear, and the $\mathrm{X}$-ray plates are good. The example of collapsed right middle is not a typical one, as in the lateral view it rather resembles interlobar fluid.

The book will be of considerable interest to those already experienced in chest diseases, representing as it does a new and original conception and interpretation of many of the everyday signs of chest illness. Although his methods are apparently of great assistance to the author, it is very likely that they wili prove confusing to the undergraduate student, and in some respects misleading.

\section{ALLERGY ANAPHYLAXIS AND IMMUNO- THERAPY}

By Bret Ratner, M.D., Baillière, Tindall \& Cox, London. 1943. Price $47 \mathrm{~s}$.

The author considers serum sickness the earliest and most easily identifiable manifestation of allergy, and that its complete study would give one the

\title{
Modern
}

\section{FOCAL THERAPY}

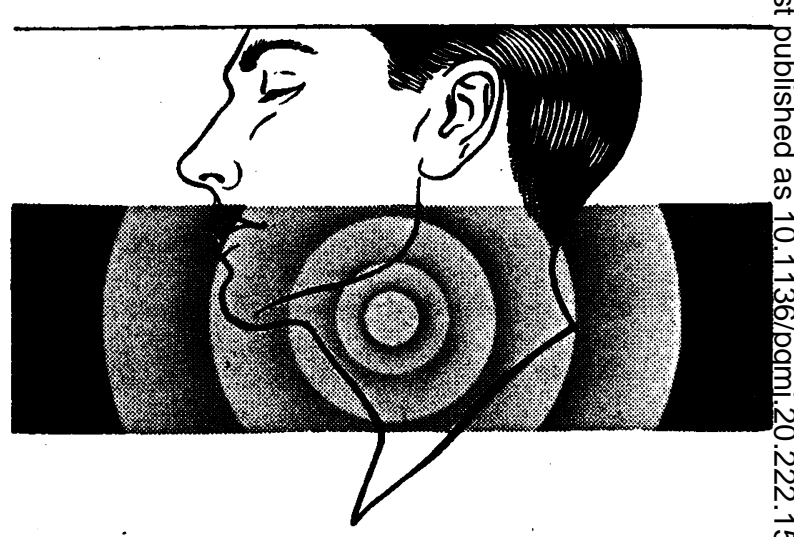

Fifty years ago Niels Finsen first tried to killy bacteria under the skin by shooting them with ultra? violet rays. He achieved brilliant and epoch-making results although his hypothesis was wrong; for thez ultra-violet rays when applied topically to the skin tissues, membranes, eliminate infections not througho their bactericidal action so much as through the losatp immunizing, activating, and regenerative effectis which they induce. In Finsen's time this therapys was a domain for specialists, exploring untrodden paths, using unwieldy equipment, devoting uncounteकू time. To-day focal ultra-violet irradiation with the Hanovia Kromayer Lamp is a well-defined therapy을 useful to every practitioner, applicable in any con sulting room, requiring little, time, and giving out? standing results in nose, throat, skin, G.U., gynae cological and surgical conditions.

To investigate these results for yourself, ask usi for a copy of the Hanovia handbook "Modern Focab Therapy" (48 pages, Io illustrations). It is free to professional enquirers.

This is one item in the all-round service (thera $\rightarrow$ peutic information, supply, and maintenance of equipment, etc.) maintained by

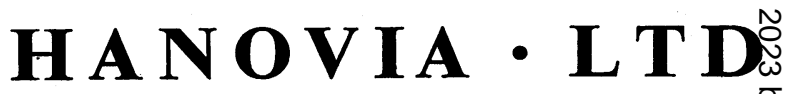

Specialists in Actinotherapy Equipment S LOU G H

London Showrooms: 3, Victoria Street, S.W.I $\stackrel{\stackrel{+}{+}}{0}$ 
genesis and fundamentals of allergy in general. Hence this book is "a treatise presenting the fundamental principles and practice governing the use of antisera, vaccines, toxoids, blood transfusions, blood substitutes and sulphonamides in the prevention and treatment of infectious diseases and of the allergic phenomena resulting from their use." Consequently it does not deal with such common allergic conditions as asthma, hay-fever, eczema or migraine.

The first part of the book deals with the materials used in the diagnosis, prophylaxis and therapy of infectious diseases, including an up-to-date discussion of the sulphonamides. Next the various infectious diseases are described alphabetically, and the immunotherapeutic methods employed. The second half of the book deals with allergy to immunotherapeutic agents, and discusses at great length the various types of serum reactions, and the reactions to blood transfusions and to drugs.

The book is well illustrated with Ratner's experiments over a period of years, and brings together into one volume most of the experimental and practical facts of anaphylaxis. The illustrations are good and a full bibliography is appended.

\section{POLISH SCIENCE AND LEARNING}

No. 4 (Medical Issue). Oxford University Press. March I944. 2s. 6d.

In the editorial to this, the fourth issue of the series, a brief account is given of the double task that lay before its authors-to present a record of Polish scientific and cultural life in the past, and to lay a foundation for the future. in collaboration with scientists of other nations. In the various original contributions which form the bulk of this volume the reader will find much interesting and valuable information about work done in Poland before the war in the field of social and preventive medicine. One of the most striking features of these articles is their vision of the future and the determination inherent in all that has been written to lay that foundation of a great future to which the Editors have referred. We commend this booklet to the medical men of our own country as worthy of their close attention. It would be invidious to eulogise individual articles in a series in which all are so well written and so instructive, but Dr. Tomaszewski's article may, perhaps, be specially mentioned as having a particular interest for us in view of the proposed changes in our own medical service which are occupying the minds of the British Government and the Medical Profession of the United Kingdom at the present time. Dr. Tomaszewski lays emphasis on the widespread need for the reconstruction of medical studies in many countries after the war, and shows how, although new ideas must be adjusted to the environment in which they will have to grow, the inevitable changes will everywhere affect the foundation of the medical educational system, which, as he points out, must be correlated with the vast social changes that are now taking place.

The accounts given in this publication of the progressive work of our Polish colleagues, and especially of the establishment since the war of the Polish medical school in Edinburgh, are most stimulating, and should be a source of encouragement to our medical reformers at home. We congratulate the Editors and the Publishers on this most welcome and valuable production.

\section{THE FOOT}

By Norman C. LAKe, M.D., M.S., F.R.C.S., 3rd Edition. Baillière, Tindall \& Cox. 1943. Price I 5 s.

In these days when the foot has of necessity replaced the motor car as a means of progression, a third edition of The Font is evidence of the increased importance of this subject. On reading the book one recalls the sage who said "Myself when young, did eagerly frequent Doctor and Saint, and heard great argument about it and about." The next line of the poem, which need not be quoted, although to some extent true, does not detract from the value of the book. The public still attributes all ills to the "Dropping of an arch," and arch supports are sold for all and sundry foot conditions. Within the profession ideas are growing that the problem is not so simple, but at present there is no general agreement as to what should replace the older theory of four degrees of flat foot. The time is therefore ripe for a discussion on these problems and many pages are devoted to this.

The author commences the book with the evolution of the foot, and has added a new chapter on the evolutionary factor in aetiology. In this he points out, how in civilised life foot movements became stereotyped by the provision of pavements to walk on, and a rigid sole which is worn. Under these conditions each step is a repetition of the last, so that with anatomical variations as a long first or second metatarsal the stresses fall repeatedly in the same places.

A new chapter is devoted to "Foot Strain and Weak Foot." This is a term suggested for many cases with foot symptoms, which in the past have been labelled flat foot, although there never were any physical signs of such a condition.

One is glad to find that he has the temerity to criticise the high heeb as worn by women: $\mathrm{He}$ states, "The heel should be the weight-bearing part of the foot; the anterior portion, relatively weak and degenerate, being merely for the preservation of balance and to help in tlie take off." The wearing of a high heel throws the weight forward on to the anterior portion.

Despite this belief, with which we agree, he still quotes Morton's staticometer results, that half the weight is taken.by the heel and half by the forepart of the foot. He does not state if the patients were standing in heeled shoes or flat. And if they wefe standing flat whether they were used to standing, maintaining balance in that position.

He also says that man's footwear of to-day cannot be subjected to much serious criticism, yet he discusses an inclined platform for prolonged standing. Presumably to nullify the effect of this same heel.

There are many additions to the book. The chapter on injuries has been enlarged by a section on Gunshot Wounds, in which this subject is treated on rather general lines. The chapter on Trench Foot and Frost Bite is interesting, as also are some of the suggestions for treatment.

The best addition to the book is an illustration of a child sleeping in the knee chest position, with the left foot in a position of marked valgus. This illustrates a discussion on foot deformities due to bad sleeping positions.

The book covers all aspects of foot conditions, so in addition can be recommended as a book of reference. 